\title{
Control of flow around a circular cylinder using a patterned surface
}

\author{
T. Hojo \\ Department of Building Technologists, \\ Institute of Technologists, Japan
}

\begin{abstract}
Controlling the flow around a circular cylinder by the use of patterned surface roughness is investigated. In this study, experimental work to reduce drag coefficient of a circular cylinder was carried out with particular attention to change in the distribution of surface roughness. Drag coefficient of a circular cylinder having discretely patterned surface was compared with uniformly roughened surface. When the circular concave and convex patterns with relative surface roughness of about $1 \%$ of the diameter were added discretely to the surface, drag coefficient of a cylinder of the patterned roughness is lower than a cylinder with uniform surface roughness of the same degree, and remains approximately constant beyond the critical Reynolds number. Measurement of the pressure distribution indicated that circular cylinders with a lumped patterned roughness made it possible to reproduce a supercritical state in lower Reynolds number range. It was considered that the lumped patterned roughness changed the flow around the circular cylinder, causing a combining of the laminar separation and the turbulent separation. The drag force characteristics of the circular cylinders were well explained by the results of the pressure distribution measurement. In conclusion, it was found that density and arrangement of lumped roughness was the key factors in controlling the drag characteristics of a circular cylinder. It seems to be possible to adjust those two factors to optimize the drag coefficientReynolds number relationship. Methods in this study to control the drag characteristics in the vicinity of the critical Reynolds number can be applied to all of cylindrical structures in various fields.
\end{abstract}

Keywords: circular cylinder, surface roughness, drag coefficient, Reynolds number, pressure distribution. 


\section{Introduction}

The flow around a circular cylinder and the drag force on it have been studied for a long time. It is well-known that its aerodynamic characteristics are affected by not only the Reynolds numbers but also by surface roughness. It is explained as follows from a viewpoint of fluid mechanics.

The surface roughness has a great effect on the drag coefficient of a circular cylinder around a critical Reynolds number range, since changes in drag coefficient are dominated by the location of a separation point. The surface roughness causes a shift in a separation point along a body where the section is circular, and this accelerates the transition into a turbulent flow range. Generally speaking, the rougher the cylinder surface, the lower the value of the critical Reynolds number, but the smaller the fall in $\mathrm{C}_{\mathrm{d}}$ through the critical range. In the high Reynolds number as post-critical range, a cylinder with a rough surface has a higher drag coefficient than one with a smooth surface. Figure 1 shows the influence of surface roughness on drag coefficient in terms of roughness coefficient $\mathrm{k} / \mathrm{D}$, where $\mathrm{k}$ is the average grain size of sand and $\mathrm{D}$ is the diameter of the circular cylinder $[1,2]$.

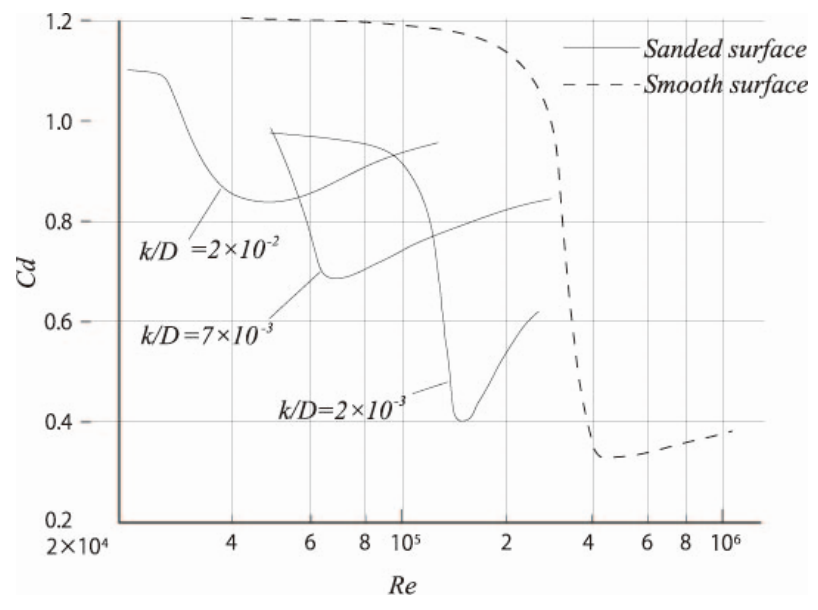

Figure 1: Drag coefficient of rough and smooth circular cylinders.

It is also known that the drag characteristics are influenced by the surface figures, such as dimpled surfaces or grooved surfaces [3-5]. However, little studies have been carried out on the flow around a circular cylinder with partially patterned surface. In this paper, drag coefficient of a circular cylinder having discretely patterned surface was compared with uniformly roughened surface. Effect of patterns were investigated in the wind tunnel test, changing arrangement shape and location of the indented patterns, up to the Reynolds number $5 \times 10^{5}$. The behaviour of the discretely patterned surface of a circular cylinder is analysed by measuring drag coefficients and pressure distribution around cylinders. 


\section{Aerodynamic characteristics of a circular cylinder with surface roughness}

\subsection{Aerodynamic properties of a circular cylinder with surface roughness}

To understand the effects of surface roughness on aerodynamic properties, a wind tunnel test was carried out $[6,7]$. Aluminium pipes with a polyethylene coating were used as a circular cylinder models. Polyethylene particles were scattered on the surface to obtain surface roughness shape similar to sanded surface.

To clarify the effects of surface roughness, models with different shapes and distributions of surface patterns were examined. Table 1 shows the experimental parameters for these models. As shown in Figure 2, a grid-like roughness was applied over the whole surface of models $B_{1}$ to $B_{3}$, and this roughness was described in terms of the depth of the grid.

Table 1: Dimensions of models.

\begin{tabular}{c|c|c|c|c}
\hline Model & $\begin{array}{c}\text { Diameter } \\
\mathrm{D}(\mathrm{mm})\end{array}$ & $\begin{array}{c}\text { Surface } \\
\text { roughness } \\
\mathrm{k}(\mu \mathrm{m})\end{array}$ & $\begin{array}{c}\text { Roughness } \\
\text { coefficient } \\
(\mathrm{k} / \mathrm{D})\end{array}$ & Remarks \\
\hline $\mathrm{A}_{1}$ & 132 & - & - & Smooth \\
\hline $\mathrm{A}_{2}$ & 122 & 30 & $2.4 \times 10^{-4}$ & Sanded surface \\
\hline $\mathrm{A}_{3}$ & 132 & 100 & $7.6 \times 10^{-4}$ & Sanded surface \\
\hline $\mathrm{A}_{4}$ & 123 & 200 & $1.6 \times 10^{-3}$ & Sanded surface \\
\hline $\mathrm{A}_{5}$ & 124 & 600 & $4.8 \times 10^{-3}$ & Sanded surface \\
\hline $\mathrm{A}_{6}$ & 127 & 1,500 & $1.2 \times 10^{-2}$ & Sanded surface \\
\hline $\mathrm{B}_{1}$ & 147 & 200 & $1.6 \times 10^{-3}$ & Grid-like pattern \\
\hline $\mathrm{B}_{2}$ & 147 & 600 & $4.1 \times 10^{-3}$ & Grid-like pattern \\
\hline $\mathrm{B}_{3}$ & 149 & 1,200 & $8.1 \times 10^{-3}$ & Grid-like pattern \\
\hline & & & &
\end{tabular}

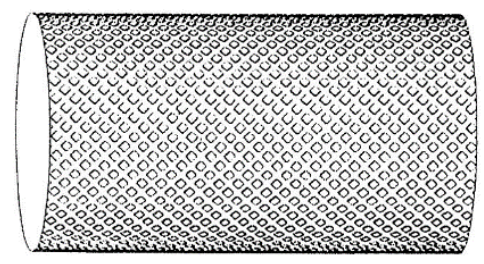

Figure 2: $\quad$ Model B.

Figures 3 and 4 show measured drag coefficient for various models. From Figure 3, it is evident that the critical Reynolds number drops as the surface roughness increases. With increasing roughness coefficient, $\mathrm{k} / \mathrm{D}$, the drag coefficient at the critical Reynolds number exceeds the drag coefficient of the smooth surface. With increasing wind velocity, the drag coefficient increases and 
has a tendency to rapidly approach 1.2 . For Model $\mathrm{A}_{6}$, which has a roughness coefficient of about $1 \%$ of its diameter, the drag coefficient became 0.9 at the critical Reynolds number of $4 \times 10^{4}$ and 1.2 at a Reynolds number of $2.2 \times 10^{5}$, respectively. The results agreed well with those reported previously within the range of roughness coefficient form $10^{-2}$ to $10^{-3}$.
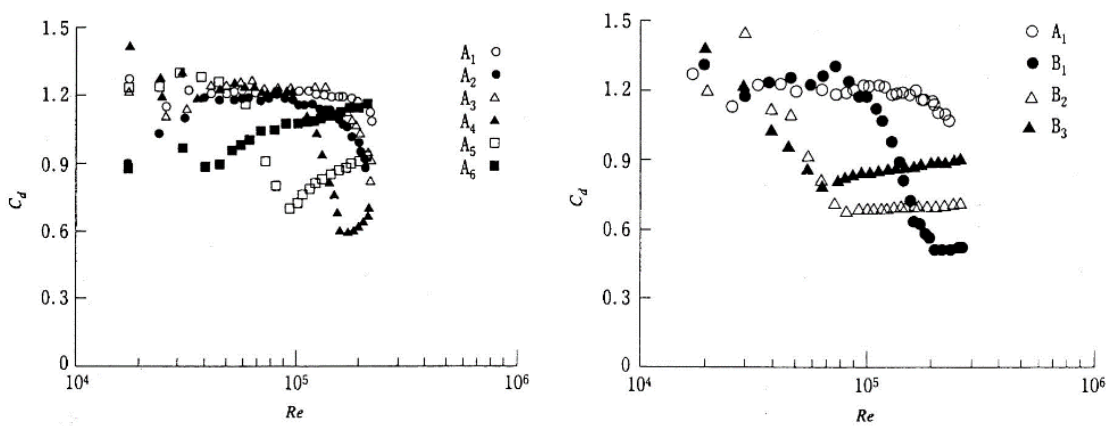

Figure 3: Drag coefficient of Model A. Figure 4: Drag coefficient of Model B.

Figure 4 shows the drag coefficient of Model $\mathrm{B}_{1}$ through $\mathrm{B}_{3}$, which were given approximately the same degree of surface roughness as Model $\mathrm{A}_{4}$ through $\mathrm{A}_{6}$, but in a grid-like pattern. The critical Reynolds number of models with this grid-like roughness decreased as the roughness coefficient increased, as with models $A_{1}$ through $\mathrm{A}_{6}$ having a uniform surface roughness. However, the drag characteristics were different from those of models $\mathrm{A}$; the drag coefficient increased gradually with increasing wind velocity. The critical Reynolds number of model $\mathrm{B}_{3}$, where the grid-like surface roughness was about $1 \%$ of the diameter, was about $6 \times 10^{4}$ and the drag coefficient was about 0.9 at a Reynolds number of $2.2 \times 10^{5}$.

This feature is possibly thought for the grid-like pattern to have a smooth part on the surface. This means that the surface roughness with a partially smooth surface gives the substantial change to the characteristic of the flow of the surface. Then, discrete shape arrangement that applied roughness to the surface having a smooth part to some degree was examined.

\subsection{Aerodynamic properties of a circular cylinder with patterned surface}

The surface figure of a concave and a convex type was designed as discrete shape arrangement, having Roughness coefficient of 0.01 . The roughness was described in terms of the depth of the concavities or the height of the convex sections. The dimensions of the models is shown Table 2. In consideration of the influence of the flow direction, the pattern was placed so as orthogonal to each other at 45 degrees with respect to the axial direction. One pattern is formed by a plurality of concave or convex part aiming to obtain a high turbulence effect by a little processing area. Namely, partially lumped concave and convex pattern were considered, showing in Figures 5 and 6. 
Table 2: Dimensions of discrete pattern models.

\begin{tabular}{|c|c|c|c|l|}
\hline Model & $\begin{array}{c}\text { Diameter } \\
\mathrm{D}(\mathrm{mm})\end{array}$ & $\begin{array}{c}\text { Surface } \\
\text { roughness } \\
\mathrm{k}(\mu \mathrm{m})\end{array}$ & $\begin{array}{c}\text { Roughness } \\
\text { coefficient } \\
(\mathrm{k} / \mathrm{D})\end{array}$ & \multicolumn{1}{|c|}{ Remarks } \\
\hline $\mathrm{C}_{1}$ & 140 & - & - & Smooth \\
\hline $\mathrm{C}_{2}$ & 140 & 1,500 & $1.1 \times 10^{-2}$ & Concave pattern \\
\hline $\mathrm{C}_{3}$ & 140 & 1,500 & $1.1 \times 10^{-2}$ & Convex pattern \\
\hline
\end{tabular}

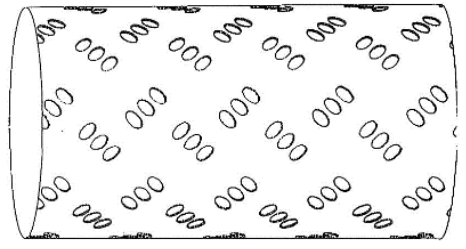

Figure 5: Model $\mathrm{C}_{2}$ (concave).

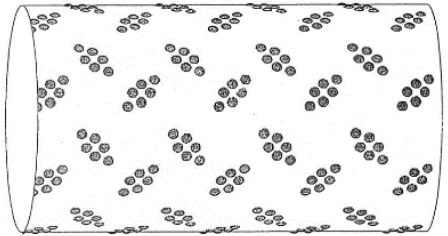

Figure 6: $\operatorname{Model~} \mathrm{C}_{3}$ (convex).

Figure 7 shows the drag coefficient of models C2 and C3, which had approximately the same degree of surface roughness as models $A_{6}$ and $B_{3}$ but applied discretely. Experimental results of model $\mathrm{C}_{1}$, which had the same smooth surface as $A_{1}$, agreed well with the previous study illustrated in Figure 1. Both $C_{2}$ and $\mathrm{C}_{3}$ had the same behavior; the critical Reynolds number and drag coefficient were $1 \times 10^{5}$ and 0.6 , respectively. Within the range of measurements up to a Reynolds number of about $5.5 \times 10^{5}$, equivalent to a wind velocity of about $55 \mathrm{~m} / \mathrm{s}$, the drag coefficient remained approximately constant.

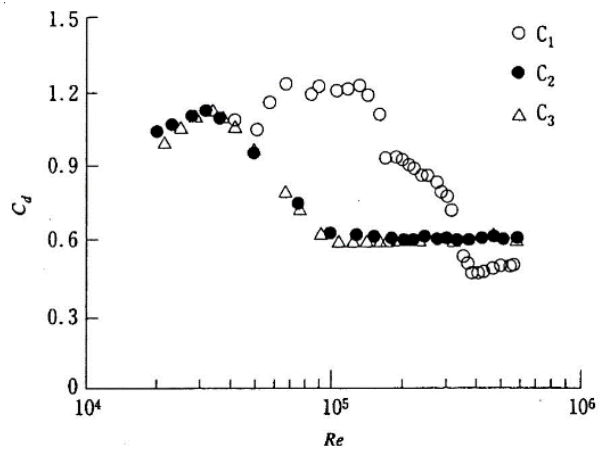

Figure 7: Drag coefficient of Model C.

Thus, as noted in a previous study, the shape and distribution of surface roughness as well as size had a strong influence on the drag characteristics of circular sections, because they changed the flow separation on the surface. The 
experiments described above indicate that the models having a discrete roughness have less drag force than that having a uniform roughness in the critical range and almost the same $C_{d}$ value in the supercritical range up to a Reynolds number of $5.5 \times 10^{5}$. It was also proved that almost equivalent drag coefficients can be obtained with discrete roughness patterns as with smooth surfaces in the supercritical range.

\subsection{Aerodynamic properties of a circular cylinder with pattern indented surface}

In this study, a single pattern shape was minimized in order to obtain uniformity of processing, because it was assumed to be manufactured by a heat processing method of the surface of polyethylene-coated cylinder. The following experiments were examined using a small indented pattern applied discretely to the surface of a cylinder. Examining a current outcome of experimental results, roughness arrangement pattern was designed. The dimensions and surface pattern of the models are shown in Table 3 and Figures 8 and 9.

Table 3: Dimensions of indented pattern models.

\begin{tabular}{c|c|c|c|c}
\hline Model & $\begin{array}{c}\text { Diameter } \\
\mathrm{D}(\mathrm{mm})\end{array}$ & $\begin{array}{c}\text { Surface } \\
\text { roughness } \\
\mathrm{k}(\mu \mathrm{m})\end{array}$ & $\begin{array}{c}\text { Roughness } \\
\text { coefficient } \\
(\mathrm{k} / \mathrm{D})\end{array}$ & Remarks \\
\hline $\mathrm{D}_{1}$ & 150 & - & - & Smooth \\
\hline $\mathrm{D}_{2}$ & 150 & 1,500 & $1.0 \times 10^{-2}$ & Indented pattern \\
\hline $\mathrm{D}_{3}$ & 150 & 1,500 & $1.0 \times 10^{-2}$ & Indented pattern \\
\hline
\end{tabular}

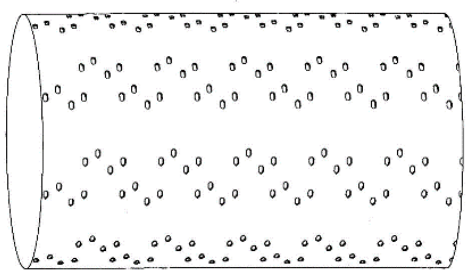

Figure 8: $\quad$ Model $\mathrm{D}_{2}$.

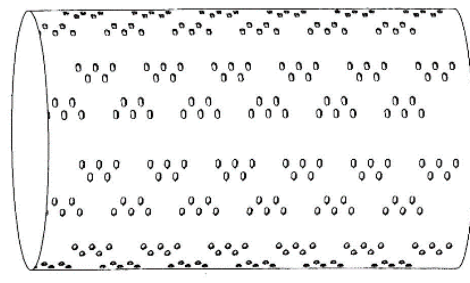

Figure 9: Model $\mathrm{D}_{3}$.

Figure 10 shows the drag coefficient of models $\mathrm{D}_{2}$ and $\mathrm{D}_{3}$. Both Model $\mathrm{D}_{2}$ and $\mathrm{D}_{3}$ had the same behaviour; the critical Reynolds number and drag coefficient were $0.9 \times 10^{5}$ and 0.6 , respectively. Experimental results of model $\mathrm{D}_{2}$ and $\mathrm{D}_{3}$ had the same characteristics as the lumped concave and convex pattern Models, though they had a tendency of slightly increasing $\mathrm{Cd}$ value in the supercritical range. 


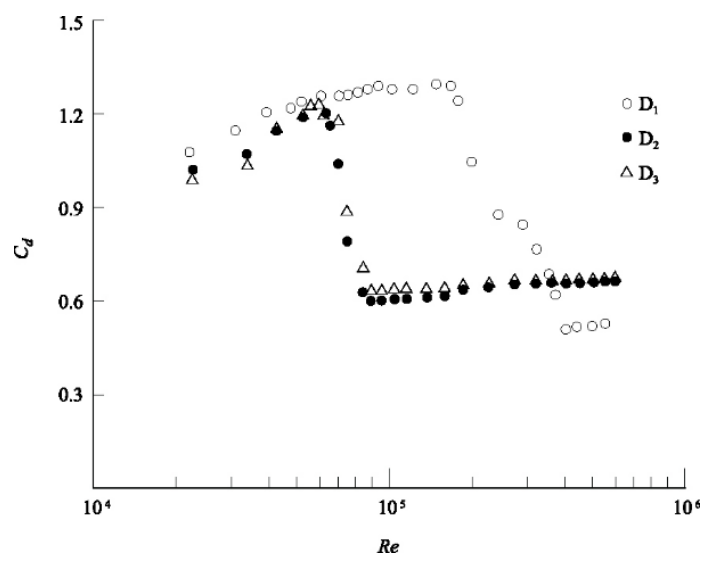

Figure 10: Drag coefficient of Model D.

This indented pattern, Model $\mathrm{D}_{2}$, has been applied to many long cable-stayed bridges, such as Tatara Bridge [8], Sutong Bridge, Stonecutters Bridge [9], Incheon Bridge and so on, as a stay-cable with a low drag coefficient and aerodynamically stable cable.

\section{Pressure distribution of pattern indented cylinder}

The aerodynamic properties of a pattern indented cylinder were analysed through studies of their pressure distribution characteristics. Pressure measurement was done by sequentially scanning 36 pressure holes drilled along the models circumference at $10^{\circ}$ intervals.

Figures 11 and 12 shows measured pressure coefficient $\mathrm{Cp}$ at the surface. With the smooth surface model $\mathrm{D}_{1}$, in the subcritical range, the location of the separation point, $\theta$, was about $80^{\circ}$ for a Reynolds number of about $0.9 \times 10^{5}$, and the pressure coefficient on the rear surface was almost constant, showing that thorough flow separation took place at the rear surface. The separation point $\theta$ was defined as transferring point where Cd curve turned from upward to level. In the supercritical range at a Reynolds number of about $5.5 \times 10^{5}$, the separation point moved backward to an angle $\theta$ of about $100^{\circ}$, and the static pressure on the rear surface was restored because of turbulent mixing, a narrower wake width, and so on.

On the other hand, with model $\mathrm{D}_{2}$, no difference in pressure coefficient at a Reynolds number of about $0.9 \times 10^{5}$ and $5.3 \times 10^{5}$ was noted, as shown in Figure 12. The separation point in this case was located at an angle $\theta$ of about $110^{\circ}$. This proves that model $\mathrm{D}_{2}$ had already entered the supercritical range at a wind velocity of about $10 \mathrm{~m} / \mathrm{s}$, which agreed well with the results of drag coefficient measurements. These results indicate that indented pattern of a surface makes it possible to reproduce the supercritical state at a Reynolds number of about $0.9 \times$ $10^{5}$. 


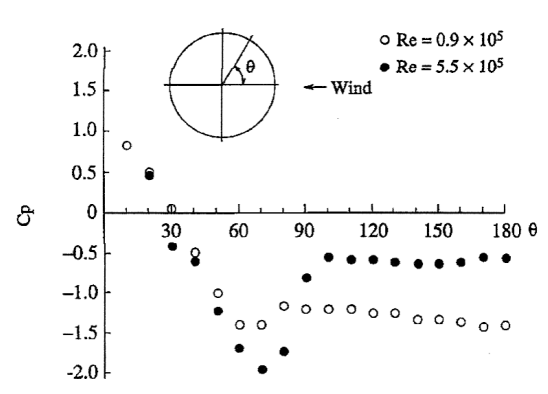

Figure 11: Pressure distribution of model $\mathrm{D}_{1}$.

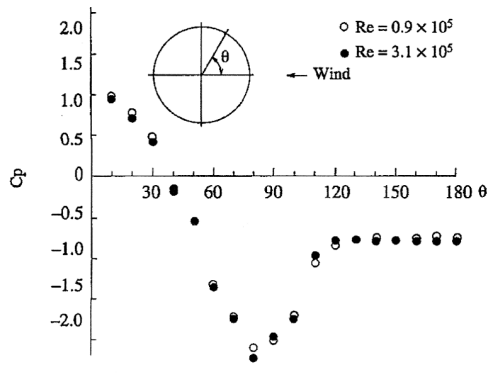

Figure 12: Pressure distribution of model $\mathrm{D}_{2}$.

\section{Control of drag coefficient by roughness distribution}

A pattern indented surfaces has a low drag characteristics beyond a critical Reynolds number range, however, the relationship between the pattern on the surface and drag characteristics has not been clearly understood yet. Then, to investigate the relationship in detail, drag characteristics of cylinder models with parametric distributed lumped roughness were measured [10].

The test was carried out using the wind tunnel having a height of $1,800 \mathrm{~mm}$ and a width of $1,800 \mathrm{~mm}$. The test models had a diameter of $82 \mathrm{~mm}$, showing Table 4 . An indented lumped roughness consisting of eight dots was applied to the surface of the cable models, each having the same configuration except density, as shown

Table 4: Dimensions of indented pattern models.

\begin{tabular}{|c|c|c|c|c|c|}
\hline Model & $\begin{array}{l}\text { Diameter } \\
\mathrm{D}(\mathrm{mm})\end{array}$ & $\begin{array}{c}\text { Surface } \\
\text { roughness } \\
\mathrm{k}(\mu \mathrm{m})\end{array}$ & $\begin{array}{c}\text { Roughness } \\
\text { coefficient } \\
(\mathrm{k} / \mathrm{D})\end{array}$ & $\begin{array}{c}\text { Pitch } \\
\text { angle }\left(\theta^{\circ}\right)\end{array}$ & $\begin{array}{c}\text { Arrangement } \\
\text { of pattern }\end{array}$ \\
\hline $\mathrm{E}$ & 82 & - & - & (smooth) & (smooth) \\
\hline D30 & 82 & 1,000 & $1.2 \times 10^{-2}$ & 30 & \multirow{3}{*}{$\begin{array}{l}\text { Dense } \\
\text { pattern }\end{array}$} \\
\hline D45 & 82 & 1,000 & $1.2 \times 10^{-2}$ & 45 & \\
\hline D90 & 82 & 1,000 & $1.2 \times 10^{-2}$ & 90 & \\
\hline M30 & 82 & 1,000 & $1.2 \times 10^{-2}$ & 30 & \multirow{3}{*}{$\begin{array}{l}\text { Medium } \\
\text { pattern }\end{array}$} \\
\hline M45 & 82 & 1,000 & $1.2 \times 10^{-2}$ & 45 & \\
\hline M90 & 82 & 1,000 & $1.2 \times 10^{-2}$ & 90 & \\
\hline $\mathrm{C} 30$ & 82 & 1,000 & $1.2 \times 10^{-2}$ & 30 & \multirow{3}{*}{$\begin{array}{l}\text { Coarse } \\
\text { pattern }\end{array}$} \\
\hline $\mathrm{C} 45$ & 82 & 1,000 & $1.2 \times 10^{-2}$ & 45 & \\
\hline C90 & 82 & 1,000 & $1.2 \times 10^{-2}$ & 90 & \\
\hline
\end{tabular}


in Figures 13 and 14. Namely, each cable model had the same indented area ratio when it had the same arrangement in circumferential direction. The diameter of one dot was $4 \mathrm{~mm}$, and depth $1 \mathrm{~mm}$, being about $1 \%$ of the depth of the diameter of the cylinder. The cylinder had the same pitched lumped roughness in longitudinal direction every $100 \mathrm{~mm}$ by staggered arrangement, although it had three types of arrangement in circumferential direction. The measurements were conducted up to the maximum wind tunnel velocity of $36 \mathrm{~m} / \mathrm{s}$, corresponding to a Reynolds numbers of $2.0 \times 10^{5}$.

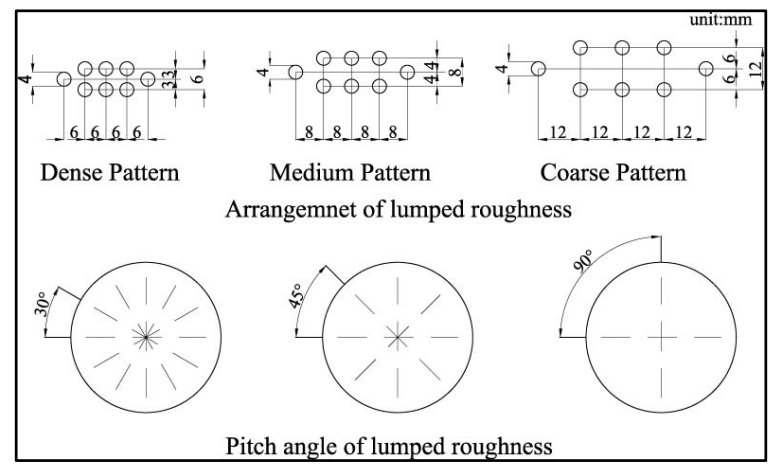

Figure 13: Arrangement of indented pattern.

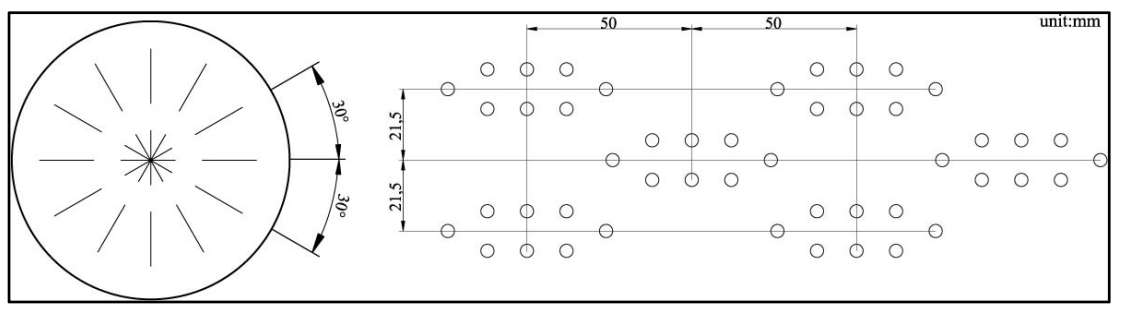

Figure 14: Pattern distribution of Model C30.

The results are summarized in Figures 15 and 16. The drag characteristics of a cylinder with a dense-dot pattern of coarse pitch arrangement tended to be similar to those of a cylinder with a smooth surface. On the other hand, the drag characteristics of a cylinder with a coarse-dot pattern of dense pitch arrangement were similar to those of a cylinder with the same roughness parameter $\mathrm{k} / \mathrm{D}$. The pitch of the roughness pattern seemed to have a more important contribution to the drag characteristics. Even when a cylinder had the same number of roughness dots on the surface, the dense-dot arrangement of the roughness pattern seemed to result in a higher critical Reynolds number and also it decreased the drag coefficient at a critical Reynolds number. Beyond a critical Reynolds number range, most of the tested patterned roughness cylinders showed a sign of almost the same constant tendency of drag coefficient as those of the models mentioned before. 

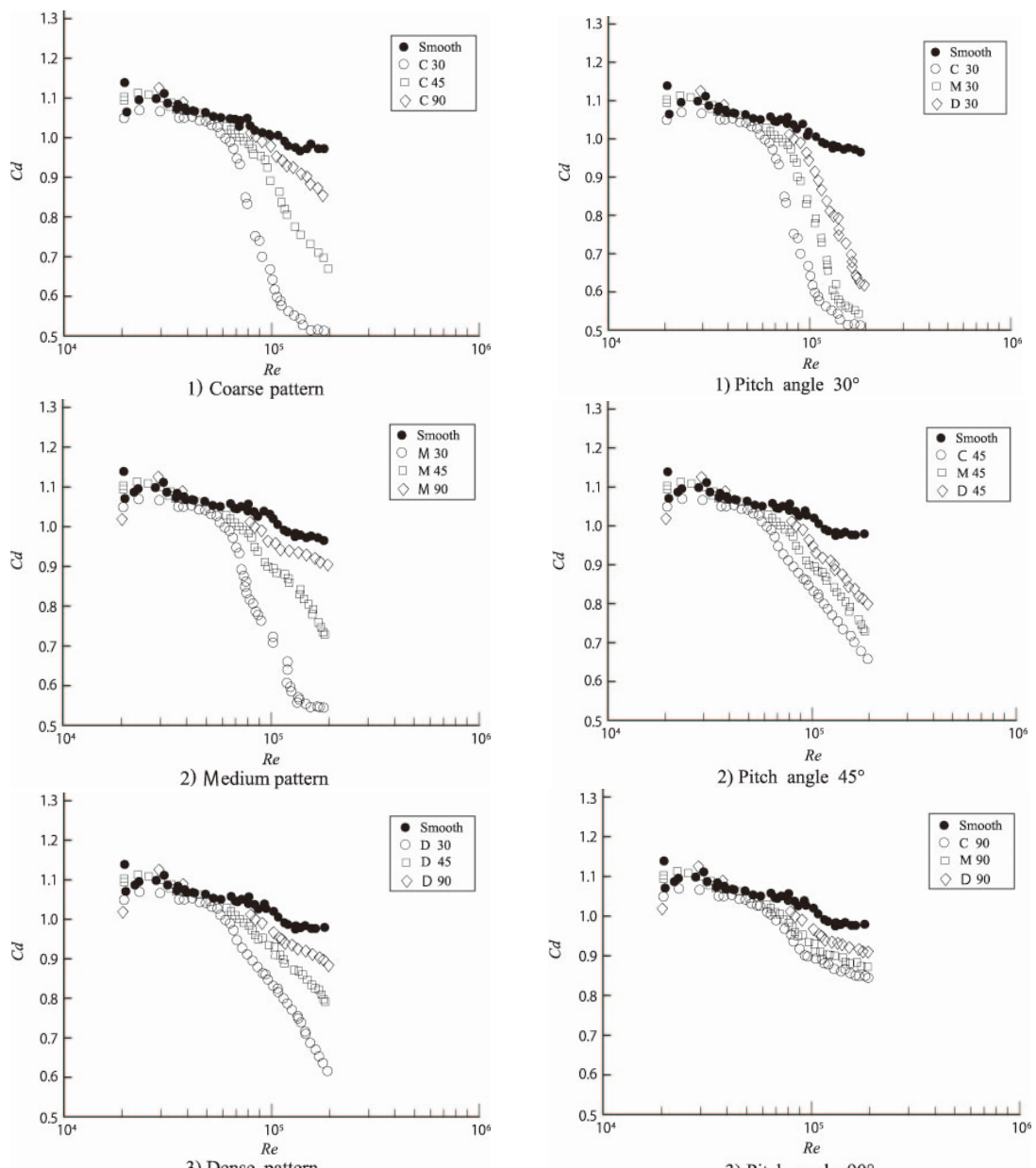

Figure 15: Effect of density.

Figure 16: Effect of pitch angle.

Effect on drag coefficient of pattern arrangement is shown in Figure 17. From experimental results, the lowest drag coefficient was obtained in model C30. Also, it has the feature similar to the indented pattern, model $\mathrm{D}_{2}$. It is thought that an almost constant drag coefficient is shown after the critical Reynolds number as well as D2, though it was measured up to a Reynolds number of $2.0 \times 10^{5}$ in this experiment.

The reason for this, it can be considered as follows; when a circular cylinder has a non-uniform roughness distribution discretely, the non-homogeneity will partially give the effect of the turbulent flow promotion. As a result, a kind of condition of equilibrium will be kept by the process of changing from the complete 
laminar boundary layer to the complete turbulent boundary layer, this leads to a constant drag coefficient characteristics after the critical Reynolds number.

Therefore, it is considered possible to adjust the density and arrangement of the dots in the patterned roughness to optimize the drag coefficient-Reynolds number relationship. It is considered that more precise optimization of the drag characteristics can be obtained with a Computational Fluid Dynamics [11].

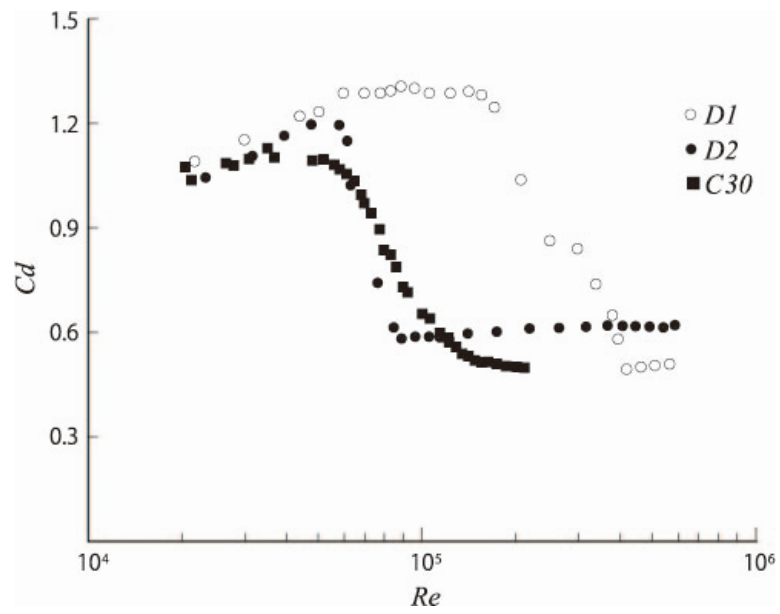

Figure 17: Effect on drag coefficient of pattern arrangement.

\section{Conclusions}

The results obtained by the study are summarized as follows:

1) Drag coefficient of a circular cylinder with a discrete surface roughness is lower than a cylinder with uniform surface roughness of the same degree, and remains approximately constant beyond the critical Reynolds number.

2) Through wind tunnel tests, it was confirmed that a lumped indented pattern with a relative surface roughness of $1 \%$ of the diameter applied discretely on a circular cylinder surface had such aerodynamic characteristics.

3) Measurement of the pressure distribution showed that a circular cylinder with a lumped patterned roughness made it possible to reproduce a supercritical state in lower Reynolds number range. It was considered that the lumped patterned roughness changed the flow around a circular cylinder, causing a combining of the laminar separation and the turbulent separation. The drag characteristics of a circular cylinder was well explained by the results of the pressure distribution measurement.

4) It was found that density and arrangement of lumped roughness was the key factors in controlling the drag characteristics of a circular cylinder. It seems to be possible to adjust those two factors to optimize the drag coefficientReynolds number relationship. 
5) Methods in this study to control the drag characteristics in the vicinity of the critical Reynolds number can be applied to all of cylindrical structures in various fields. Furthermore, it is considered that more precise optimization of the drag characteristics can be obtained with a Computational Fluid Dynamics.

\section{References}

[1] Achenbach,E., Influence of surface roughness on the cross-flow around a circular cylinder, J. Fluid Mech. Vol.46, pp. 321-335, 1971

[2] Achenbach,E., Experiments on the flow past spheres at very high Reynolds numbers, J. Fluid Mech. Vol.54, pp. 565-575, 1972

[3] Beraman,P., and Harvey,J., Control of cylinder flow by the use of dimples, AIAA Journal, Vol.31, pp. 1753-1756, 1993

[4] Kimura,T., and Tsutahata,M., Fluid dynamics effects of grooves on circular cylinder surface, AIAA Journal, Vol.29, pp. 206-2268, 1991

[5] Butt,U., and Egbers,C., Aerodynamic characteristics of flow over circular cylinders with patterned surface, International Journal of Material and Manufacturing, Vol.1, pp. 121-125, 2013

[6] Miyata,T., Yamada,H. and Hojo,T., Experimental study on aerodynamic characteristics of cables with patterned surfaces, Journal of Structural Engineering, Vol.40A, pp. 1065-1076, 1994

[7] Miyata,T., Yamada,H. and Hojo,T., Aerodynamic response of PE stay cables with pattern-indented surface, Proceedings of International Conference on Cable-Stayed and Suspension Bridges, pp. 515-522, 1994

[8] Miyata,T., Yamada,H., Fujiwara,T. and Hojo,T., Wind-resistant design of cables for the Tatara Bridge, Proceedings of International Association of Bridge and Structural Engineering, pp. 25-30, 1998

[9] Kite,S., Yeung,N. and Vejrum,T., Stonecutters Bridge, Hong Kong: stay cable and geometry control, Bridge Engineering, ICE Proceedings, Vol.165, pp. 59-65, 2012

[10] Hojo,T., Yamazaki,S. and Okada,H., Development of low-drag aerodynamically stable cable with indented processing, Nippon Steel Technical Report No.82, pp. 15-22, 2000

[11] Aoki,K., Muto,K., Okanaga,H. and Nakayama,Y., Aerodynamic characteristics and flow pattern on dimples structure of a sphere, Proceedings of $10^{\text {th }}$ International Conference on Fluid Control, Measurement, and Visualization pp. 1-10, 2009 